\title{
Electrospray lonization-Mass Spectrometry of Synthetic Polymers Functionalized with Carboxylic Acid End-Groups
}

Tobias Nitsche1,2, Margaret M. Sheil11, James P. Blinco ${ }^{1,2, *}$, Christopher Barner-Kowollik',2,* and Stephen J. Blanksby ${ }^{3, *}$

1. School of Chemistry and Physics, Queensland University of Technology, 2 George Street, Brisbane, QLD 4000 (Australia).

2. Centre for Materials Science, Queensland University of Technology, 2 George Street, Brisbane, QLD 4000 (Australia).

3. Central Analytical Research Facility, Queensland University of Technology, 2 George Street, Brisbane, QLD 4000 (Australia).

Corresponding authors

* E-mail: christopher.barnerkowollik@qut.edu.au

*E-mail: stephen.blanksby@qut.edu.au

*E-mail: j.blinco@qut.edu.au

\section{Contents}

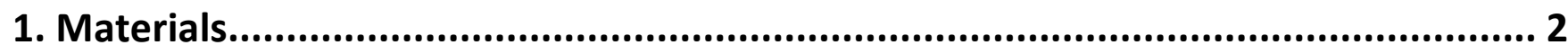

2. Characterization Methods and Instrumentation ............................................. 2

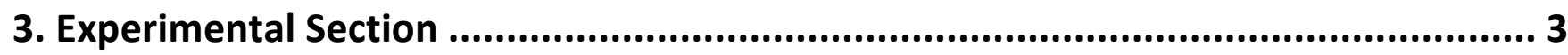

4. Variation of ionization and measurement conditions ....................................... 11

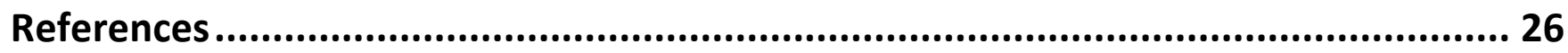




\section{Materials}

Styrene (>99\%), 2-(2-carboxyethylsulfanylthiocarbonylsulfanyl)propionic acid, 2-(dodecylthiocarbonothioylthio)2-methylpropionic acid, and ammonia solution ( $7 \mathrm{~N}$ in methanol) were purchased from Sigma-Aldrich.

Chloromethylstyrene (CMS, technical grade, 90\%), tetrahydrofuran (THF, HPLC grade), methanol (Optima LC-MS grade) and dichloromethane were purchased from Thermo Fisher Scientific.

All materials were reagent grade and used as received, unless stated otherwise. Styrene was de-inhibited by passing over a column of activated basic alumina (Ajax) directly prior to use. CMS was dissolved in diethyl ether, washed three times with $0.5 \%$ aqueous $\mathrm{NaOH}$ solution and dried over sodium sulfate. The residual solvent was removed under reduced pressure and the remaining CMS was distilled under vacuum at $95^{\circ} \mathrm{C}$.

\section{Characterization Methods and Instrumentation}

Size exclusion chromatography (SEC). The SEC measurements were conducted on a PSS SECurity system consisting of a PSS SECurity Degasser, PSS SECurity TCC6000 Column Oven $\left(35^{\circ} \mathrm{C}\right)$, PSS SDV Column Set $(8 \times 150 \mathrm{~mm} 5 \mu \mathrm{m}$ Precolumn, 8 x 300 mm 5 um Analytical Columns, $100000 \AA$, $1000 \AA ̊$ and $100 \AA$ ) and an Agilent 1260 Infinity Isocratic Pump, Agilent 1260 Infinity Standard Autosampler, Agilent 1260 Infinity Diode Array and Multiple Wavelength Detector (A: 254 nm, B: 360 nm), Agilent 1260 Infinity Refractive Index Detector $\left(35^{\circ} \mathrm{C}\right)$. HPLC grade THF, stabilized with BHT, is used as eluent at a flow rate of $1 \mathrm{~mL} \mathrm{~min}{ }^{-1}$. All samples were passed over $0.22 \mu \mathrm{m}$ PTFE membrane filters. Narrow disperse linear poly(styrene) $\left(\mathrm{M}_{\mathrm{n}}: 266 \mathrm{~g} \mathrm{~mol}^{-1}\right.$ to $\left.2.52 \times 10^{6} \mathrm{~g} \mathrm{~mol}^{-1}\right)$ and poly(methyl methacrylate) $\left(\mathrm{M}_{\mathrm{n}}: 202 \mathrm{~g} \mathrm{~mol}^{-1}\right.$ to $2.2 \times 10^{6} \mathrm{~g} \mathrm{~mol}^{-1}$ ) standards (PSS ReadyCal) were used as calibrants. Molecular weight and dispersity analysis was performed in PSS WinGPC UniChrom software (version 8.2). The $M_{n}$ determination via polymer-specific calibration has been investigated by testing identical polymer standards in different laboratories, which showed a standard deviation between $15-30 \%{ }^{1}$

Electrospray ionization-mass spectrometry (ESI-MS). Mass spectra were recorded on a Q-Exactive Biopharma (Orbitrap) mass spectrometer (Thermo Fisher Scientific, Bremen, Germany) equipped with a HESI-II electrospray ionization probe fitted with a 32-gauge needle insert (0.004 in. inner diameter). The instrument was calibrated in the $m / z$ range $74-1822$ using premixed calibration solutions (Thermo Scientific) and for the high mass mode in the $\mathrm{m} / \mathrm{z}$ range of 600-8000 using ammonium hexafluorophosphate solution. If no contradicting description is given, the following conditions were utilized:

Samples were prepared in solution to a concentration of $0.1 \mathrm{mg} \mathrm{mL}^{-1}$ using either a mixture of THF/MeOH (3:2) or $\mathrm{DCM} / \mathrm{MeOH}$ (3:2), doped with $700 \mu \mathrm{M}$ ammonia. Samples were infused into the ESI source at a flow rate of $5 \mu \mathrm{L} \mathrm{min}{ }^{1}$. The ESI-MS was operated in negative ion mode using a constant spray voltage of $-3.2 \mathrm{kV}$, a sheath 
gas setting of 8 (arbitrary units) and an auxiliary gas flow rate 0 (arbitrary units). The capillary temperature was set to $320^{\circ} \mathrm{C}$, the S-lens RF level was set to 130 , and the auxiliary gas heater temperature was set to $30^{\circ} \mathrm{C}$. The AGC target was set to $1 \times 10^{6}$, the maximum injection time was set to $200 \mathrm{~ms}$ and spectra were acquired using 5 microscans.

Nanospray experiments were carried out on a Nanospray Flex ion source, equipped with a stainless steel emitter needle with an inner diameter of $30 \mu \mathrm{m}$. The flowrate was tested between $0.1-1.0 \mu \mathrm{L} \mathrm{min}^{-1}$ and the spray voltage was adjusted accordingly $(-1.2-2.0 \mathrm{kV})$.

\section{Experimental Section}

\section{Poly(styrene-co-chloromethylstyrene) (PS/CMS)}

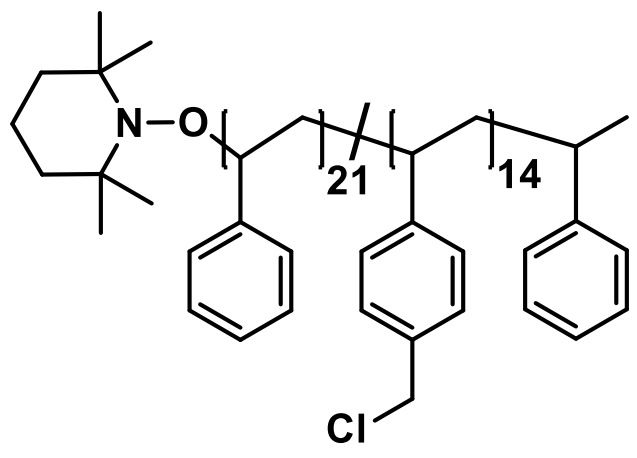

$164 \mathrm{mg}$ 2,2,6,6-Tetramethyl-1-(1-phenylethoxy)piperidine $\quad(0.628$ mmol, 1.00 eq.) and $9.8 \mathrm{mg}$ TEMPO (0.0628 mmol, 0.10 eq.) were dissolved in a mixture of $4.30 \mathrm{~mL}$ styrene $(3.92 \mathrm{~g}, 37.7 \mathrm{mmol}, 60.0 \mathrm{eq}$.) and $2.63 \mathrm{~mL}$ chloromethyl styrene (2.85 g, $18.9 \mathrm{mmol}, 30.0$ eq.). The reaction mixture was degassed via four freeze-thaw cycles. The reaction was carried out for 6 hours at $125^{\circ} \mathrm{C}$. The crude mixture was diluted with THF and precipitated dropwise into $1 \mathrm{~L}$ methanol. The precipitate was collected by filtration and dried at $35^{\circ} \mathrm{C}$ under vacuum. 


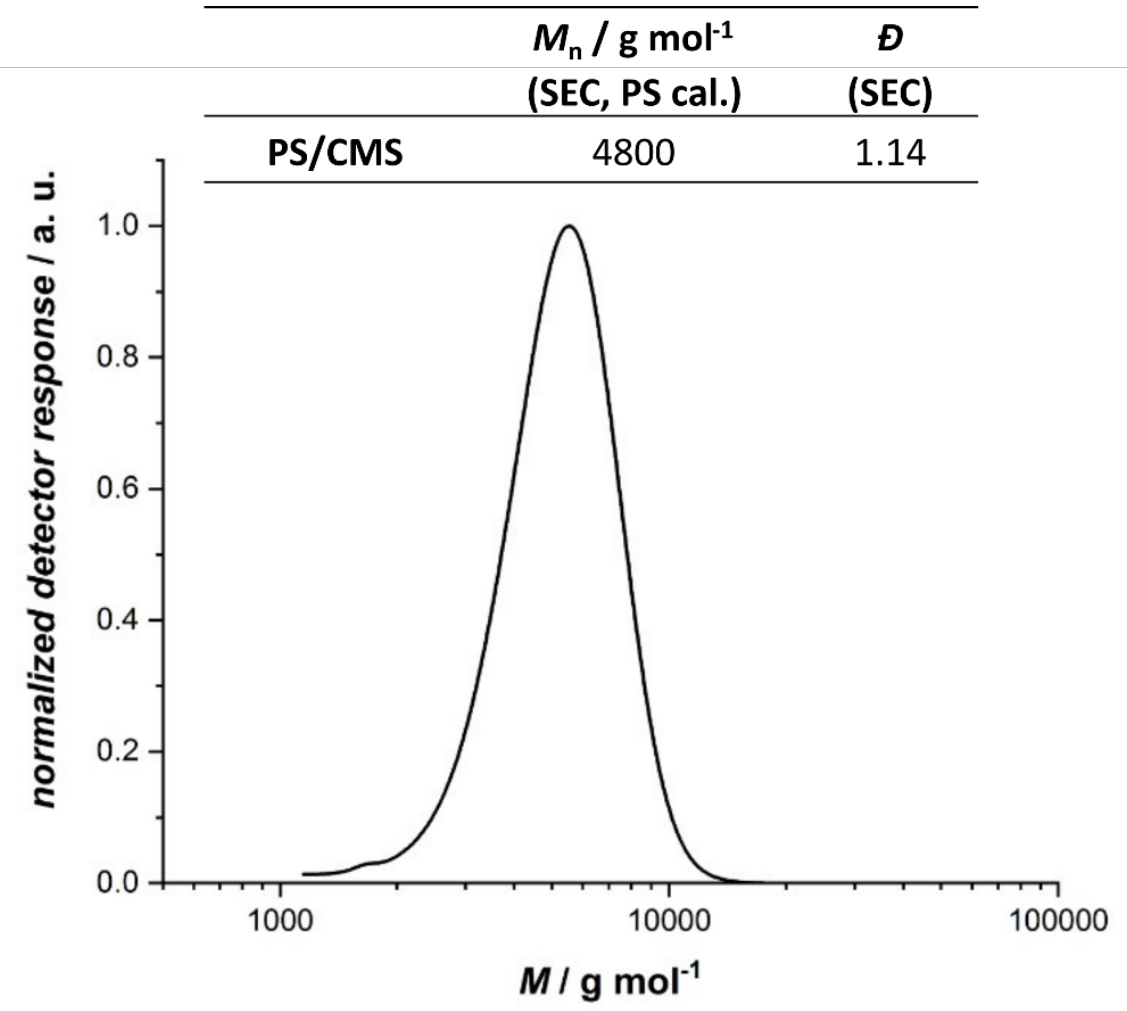

Figure S1. SEC trace of PS/CMS in THF using PS calibration.

\section{DoPAT Poly(styrene) (PS_CO $\left.{ }_{2} \mathrm{H}\right)$}<smiles>CC(C)(C)C(=O)SC(=S)SC(C)(C)C(=O)O</smiles>

$350.6 \mathrm{mg}$ 2-(Dodecylthiocarbonothioylthio)propionic acid (1.14 mmol, 1.00 eq.) and $18.7 \mathrm{mg}$ Azobisisobutyronitrile $(0.11 \mathrm{mmol}, 0.10 \mathrm{eq.}$ ) were dissolved in $26.14 \mathrm{~mL}$ styrene $(23.77 \mathrm{~g}, 228.2 \mathrm{mmol}, 200.0$ eq.). The reaction mixture was separated equally into four crimp vials and deoxygenated via nitrogen bubbling. The reaction was carried out in a heating block at $70^{\circ} \mathrm{C}$ over 5.75 hours. The crude mixture was precipitated three times into ice-cold methanol to remove excess monomer.

Table S1. Monocarboxyl polystyrene synthesized via RAFT polymerization and characterized by SEC, calibrated with narrow polystyrene standards.

$$
\begin{array}{ccc}
M_{\mathrm{n}} \text { (SEC, PS cal.) } & M_{\mathrm{w}} \text { (SEC, PS cal.) } & \oplus \text { (SEC) } \\
{\left[\mathrm{g} \mathrm{mol}^{-1}\right]} & {\left[\mathrm{g} \mathrm{mol}^{-1}\right]} &
\end{array}
$$

PS_CO ${ }_{2} \mathrm{H} \quad 4800 \quad 5200 \quad 1.08$


The RI detector data $\left(I\left(M_{\mathrm{w}, \mathrm{i}}\right)\right)$ was corrected to display the $M_{\mathrm{n}}$ instead by a simple correction:

$$
I\left(M_{n, i}\right)=\frac{I\left(M_{w, i}\right)}{M_{i}}
$$

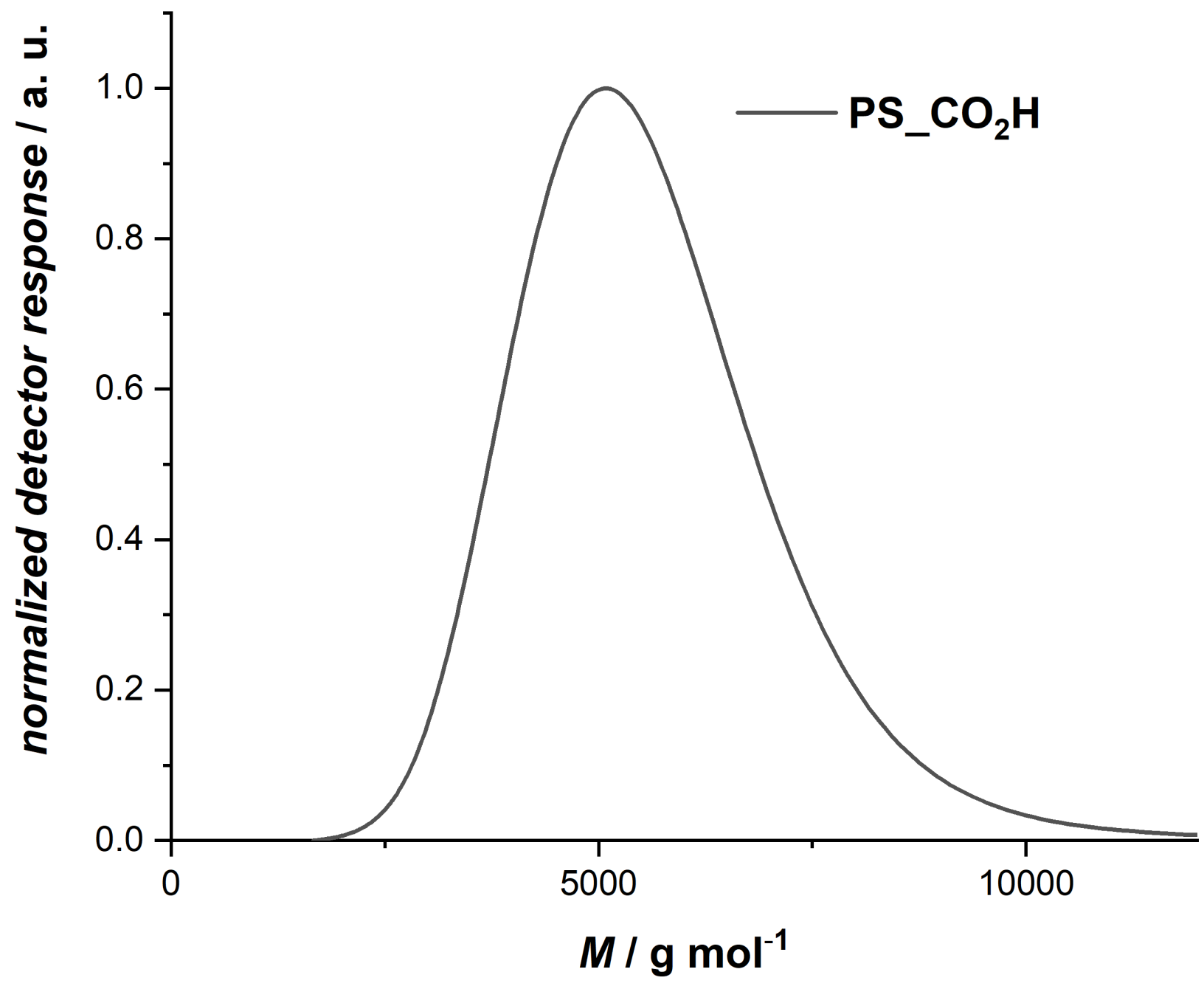

Figure S2. SEC traces of the synthesized carboxy initiated PS polymers ( $\left.\mathrm{PS}_{-} \mathrm{CO}_{2} \mathrm{H}\right)$ in THF utilizing the PS calibration, corrected to display the $M_{\mathrm{n}}$.

The monofunctionalized polystyrene PS_ $\mathrm{CO}_{2} \mathrm{H}$ was fractionated via preparative SEC resulting in four fractions labelled in the following with the number of the fraction. 


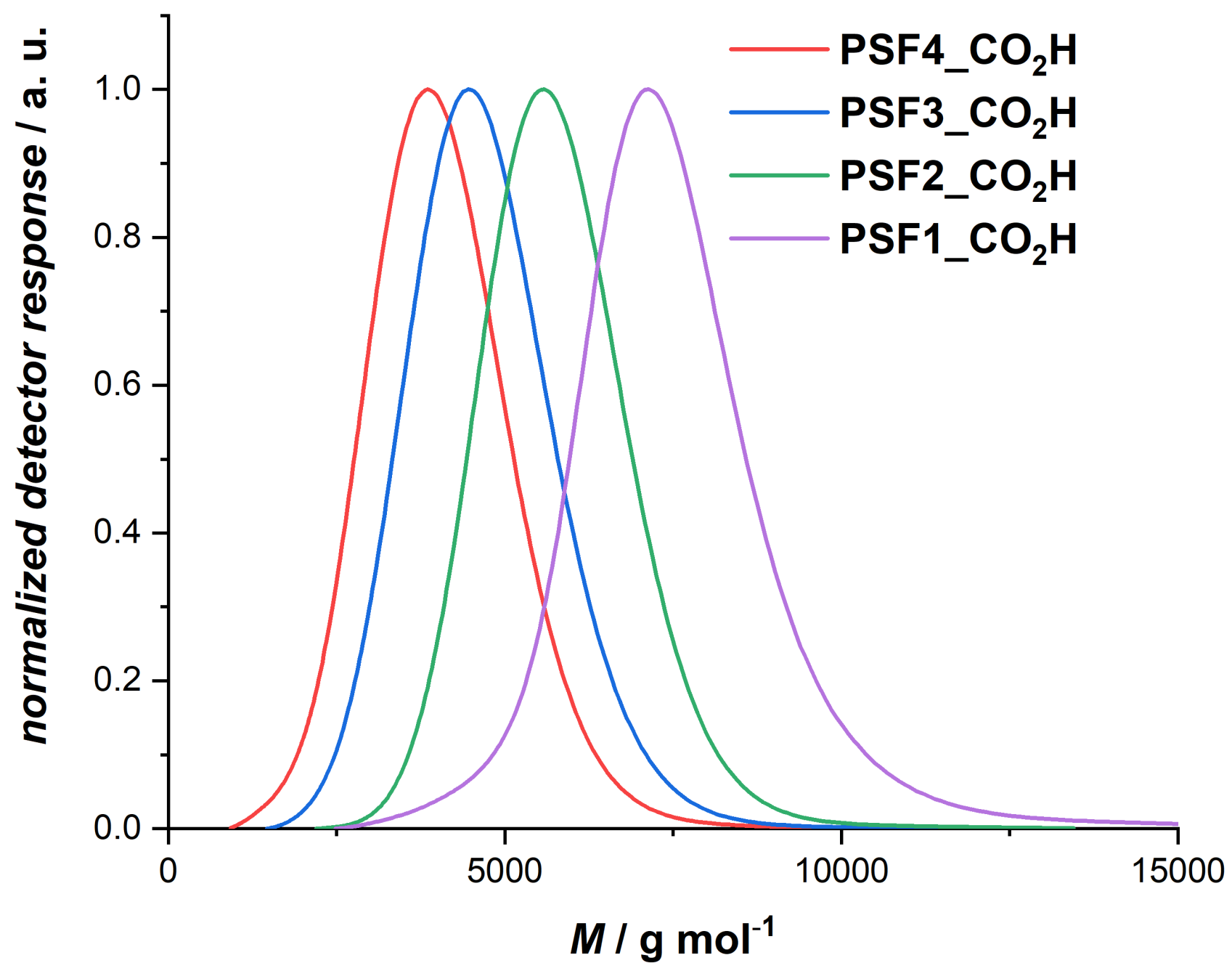

Figure S3. SEC traces of the fractions 1-4 of the preparative SEC fractionation of the carboxyl functionalized polystyrene $\mathrm{PS}_{-} \mathrm{CO}_{2} \mathrm{H}$, evaluated via PS-calibrated SEC.

Dicarboxyl Polystyrene $\left(\mathrm{HO}_{2} \mathrm{C} \_\right.$PS_ $\left.\mathrm{CO}_{2} \mathrm{H}\right)$<smiles>CC(C)C(=O)O</smiles>

254.0 mg 2-(2-Carboxyethylsulfanylthiocarbonylsulfanyl)propionic acid (0.98 mmol, 1.00 eq.) and $16.2 \mathrm{mg}$ azobisisobutyronitrile $(0.10$ $\mathrm{mmol}, 0.10$ eq.) were dissolved in $22.55 \mathrm{~mL}$ styrene $(20.50 \mathrm{~g}, 196.83$ mmol, 200.0 eq.). The reaction mixture was separated equally into five crimp vials and deoxygenated via nitrogen bubbling. The reaction was carried out in a heating block at $70{ }^{\circ} \mathrm{C}$. To prepare a set of differently sized polymers the reactions were stopped at different times by removing the sample from the heating block and rapidly decreasing the temperature. The crude mixtures were precipitated three times into ice-cold methanol to remove excess monomer. To simplify the manuscript, only the smallest sample, stopped after 5.5 hours is depicted. 
Table S2. Dicarboxyl polystyrene $\left(\mathrm{HO}_{2} \mathrm{C} \_\right.$PS_C $\left.\mathrm{CO}_{2} \mathrm{H}\right)$ synthesized via RAFT polymerization and characterized by SEC, calibrated with narrow polystyrene standards.

\section{reaction time $\quad M_{\mathrm{n}}$ (SEC, PS cal.) $\quad M_{\mathrm{w}}$ (SEC, PS cal.)}

[h]

$\left[\mathrm{g} \mathrm{mol}^{-1}\right.$ ]

$\left[\mathrm{g} \mathrm{mol}^{-1}\right]$

$\boldsymbol{\oplus}$ (SEC)

\begin{tabular}{|c|c|}
\hline $\mathrm{HO}_{2} \mathrm{C}$ _PS_CO${ }_{2} \mathrm{H}$ & 5.5 \\
\hline
\end{tabular}

The RI detector data $\left(I\left(M_{\mathrm{w}, \mathrm{i}}\right)\right)$ was corrected to display the $M_{\mathrm{n}}$ instead by a simple correction:

$$
I\left(M_{n, i}\right)=\frac{I\left(M_{w, i}\right)}{M_{i}}
$$

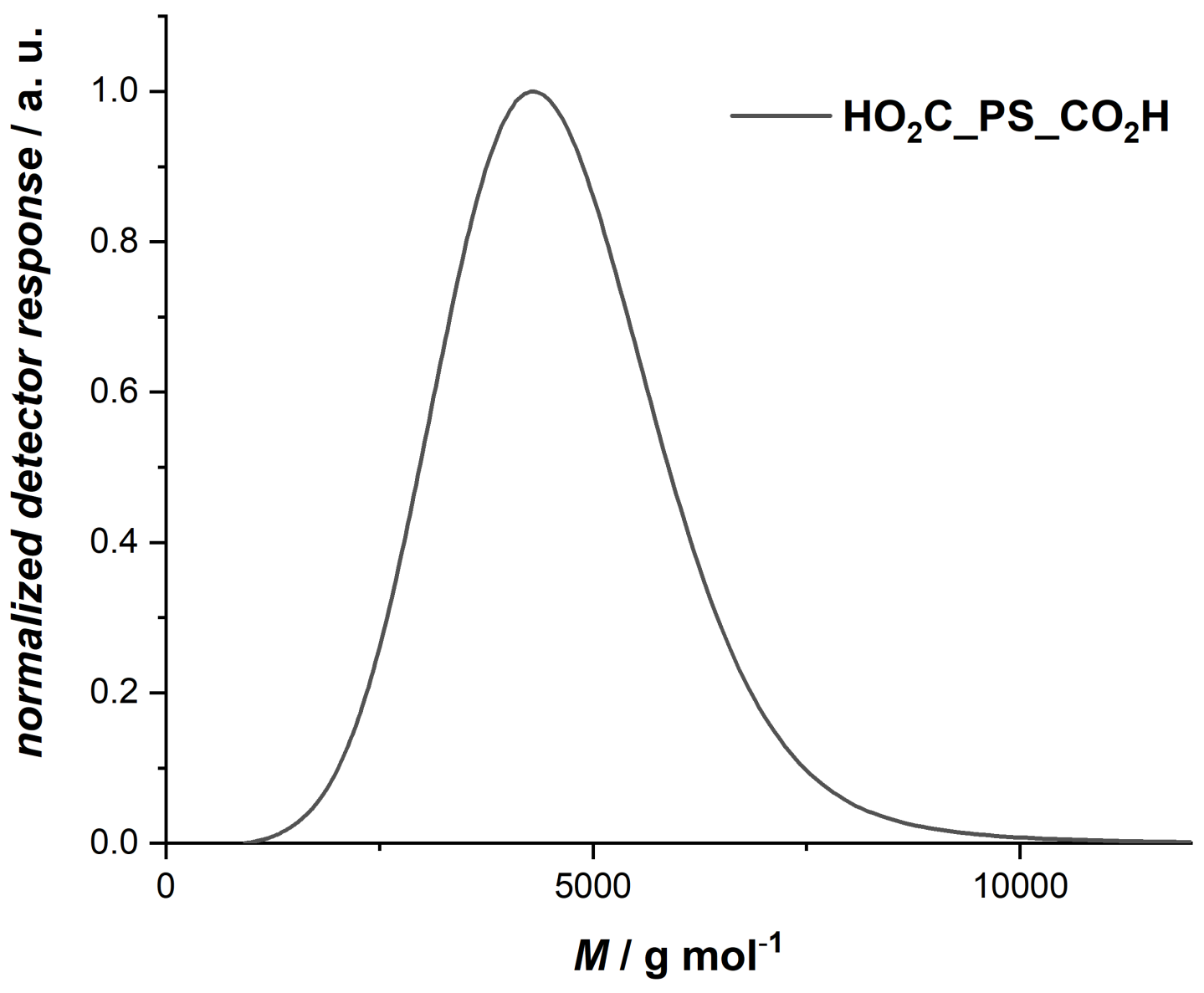

Figure S4. SEC traces of the synthesized dicarboxy polystyrene $\mathrm{HO}_{2} \mathrm{C} \_\mathrm{PS} \_\mathrm{CO}_{2} \mathrm{H}$ in THF utilizing the PS calibration, corrected to display the $M_{\mathrm{n}}$.

The dicarboxyl functionalized polystyrene $\mathrm{HO}_{2} \mathrm{C}$-PS_ $\mathrm{CO}_{2} \mathrm{H}$ was fractionated via preparative SEC resulting in four fractions labelled in the following with the number of the fraction (F1-F4). 


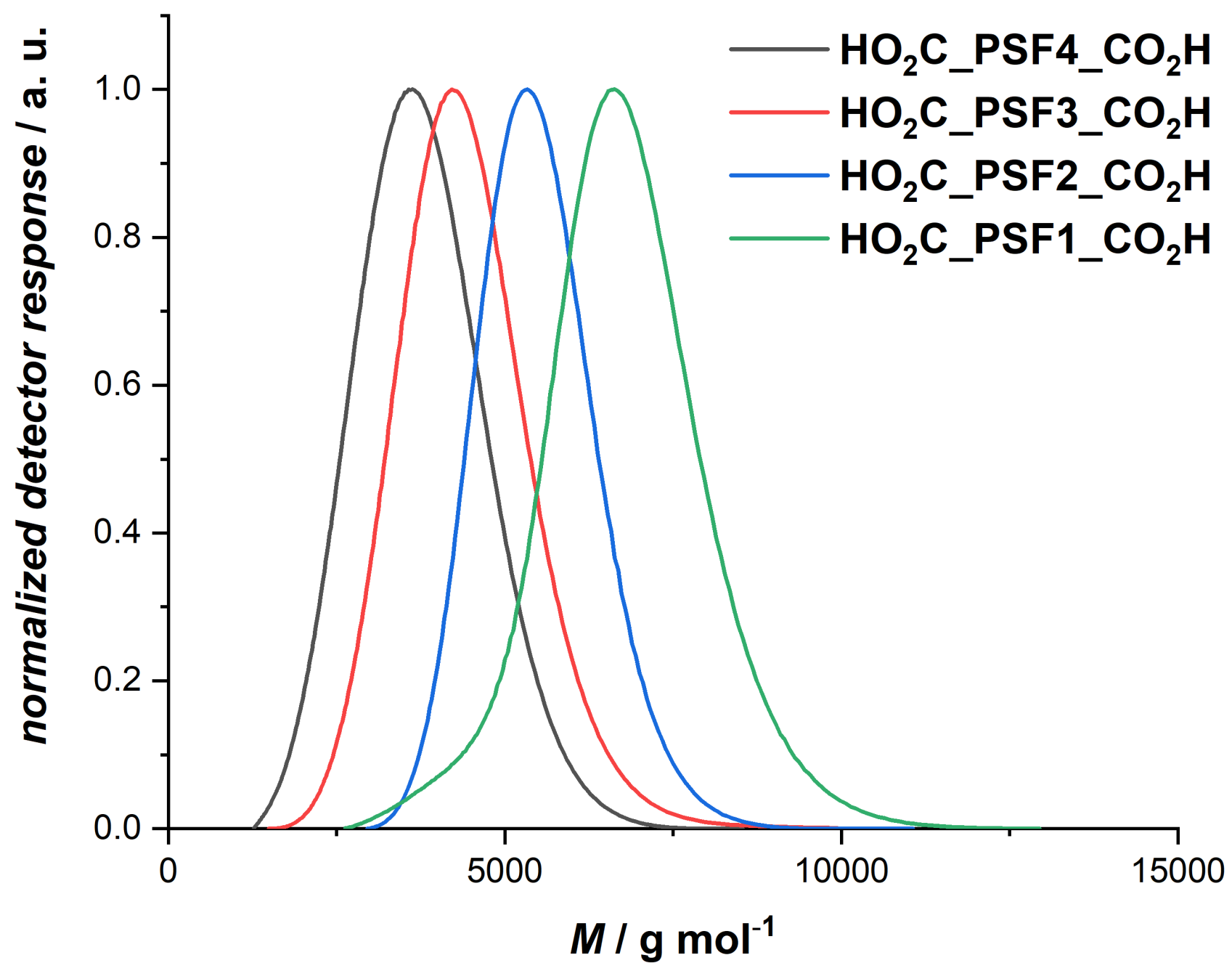

Figure S5. SEC traces of the fractions 1-4 of the preparative SEC fractionation of the dicarboxyl-functionalized polystyrene $\mathrm{HO}_{2} \mathrm{C} \_\mathrm{PS}_{-} \mathrm{CO}_{2} \mathrm{H}$, evaluated via PS-calibrated SEC.

For the comparison of the ionization and analysis of mono- and difunctionalized polystyrenes with narrow distributions, size-matched fractions centering around 5000 and $8000 \mathrm{~g} \mathrm{~mol}^{-1}$ were compared. These fractions were received via fractionation of different parent polymers that are not discussed in this manuscript to avoid confusion. The SEC traces of the fractions are compared in Figures S6/S7. 


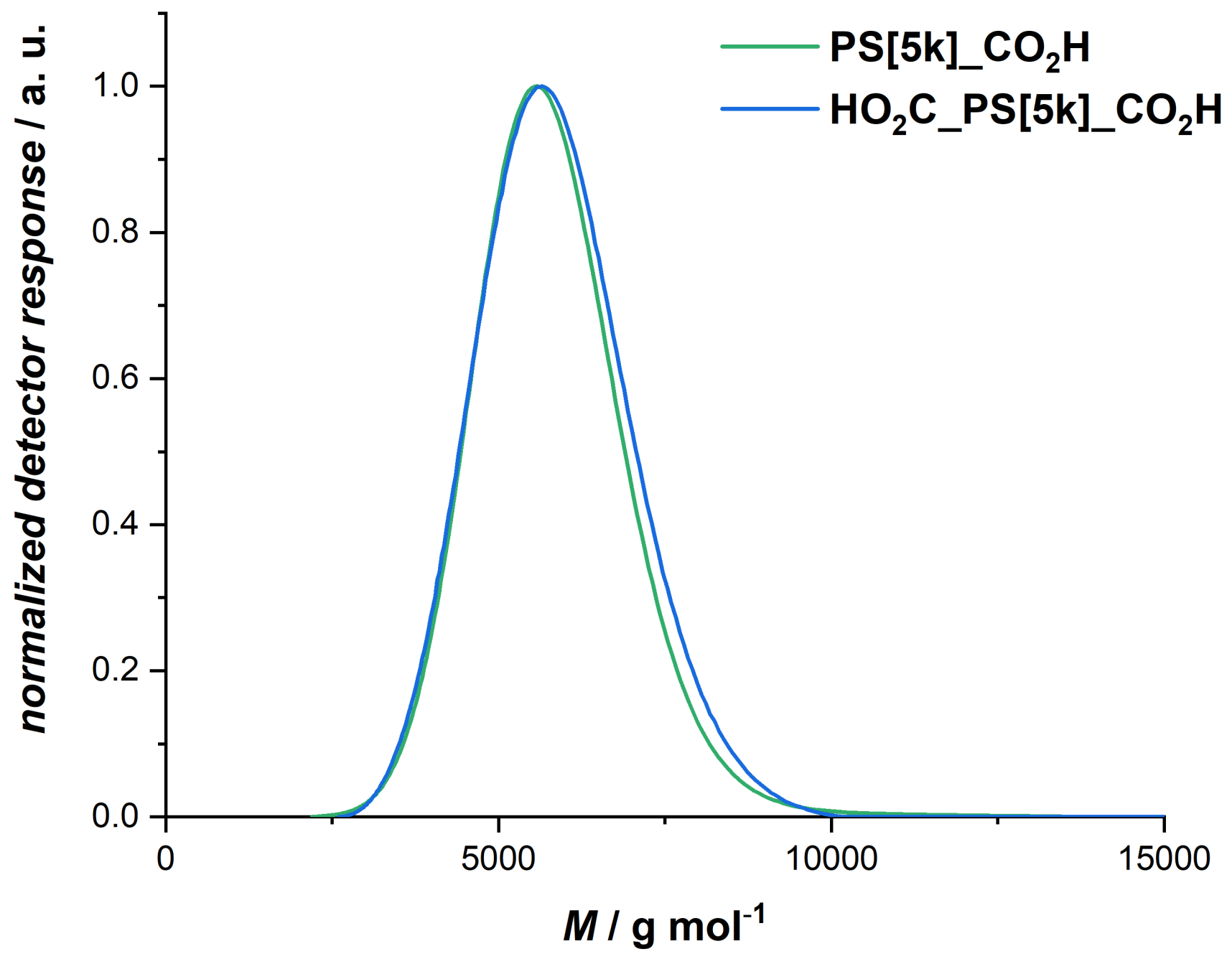

Figure S6. SEC traces of the smaller molecular mass pair of monofunctionalized PS and difunctionalized PS, measured in THF and calibrated via PS calibration, to compare the ionization behavior. 


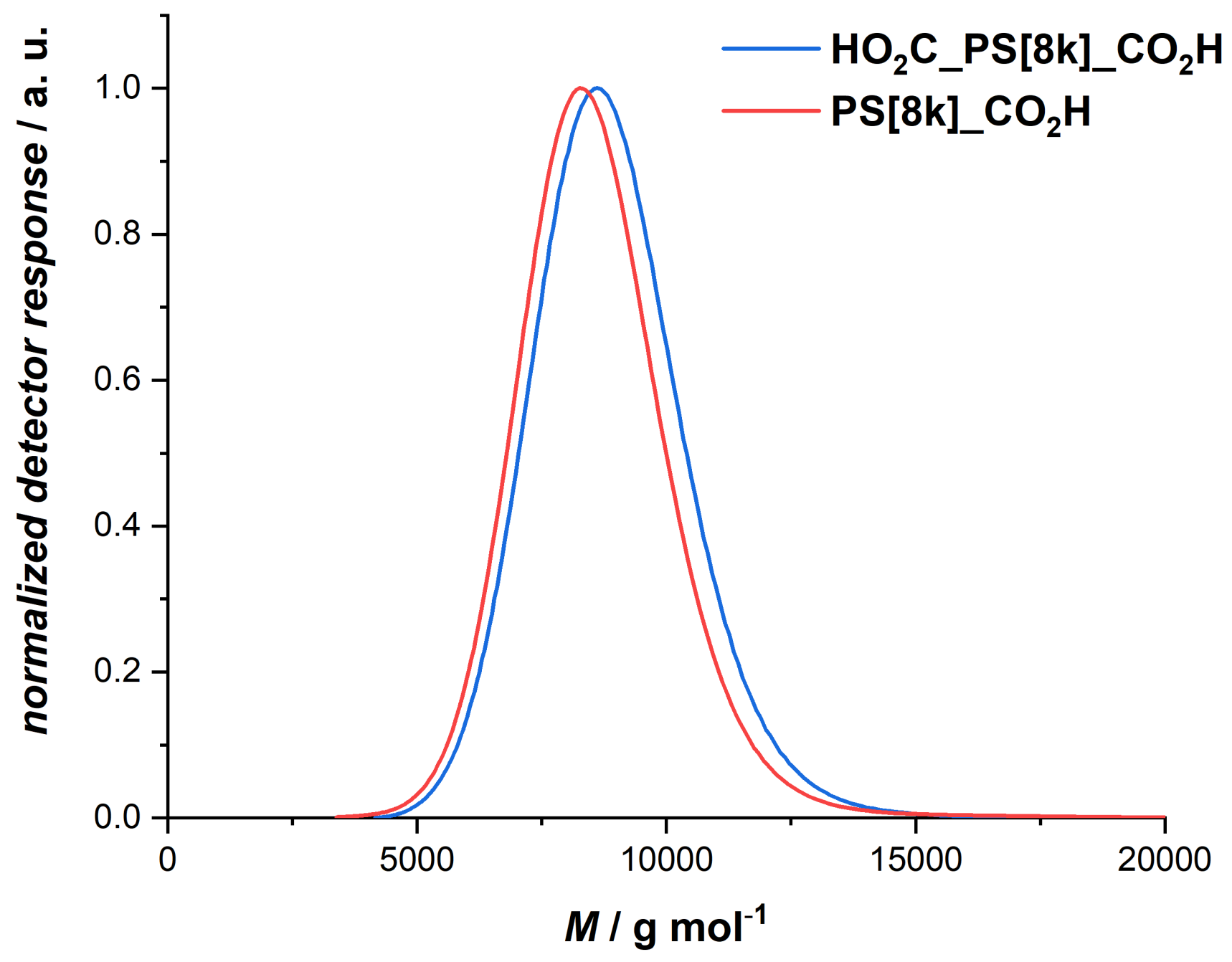

Figure S7. SEC traces of the higher molecular mass pair of monofunctionalized PS and difunctionalized PS, measured in THF and calibrated via PS calibration, to compare the ionization behavior. 


\section{Variation of ionization and measurement conditions}
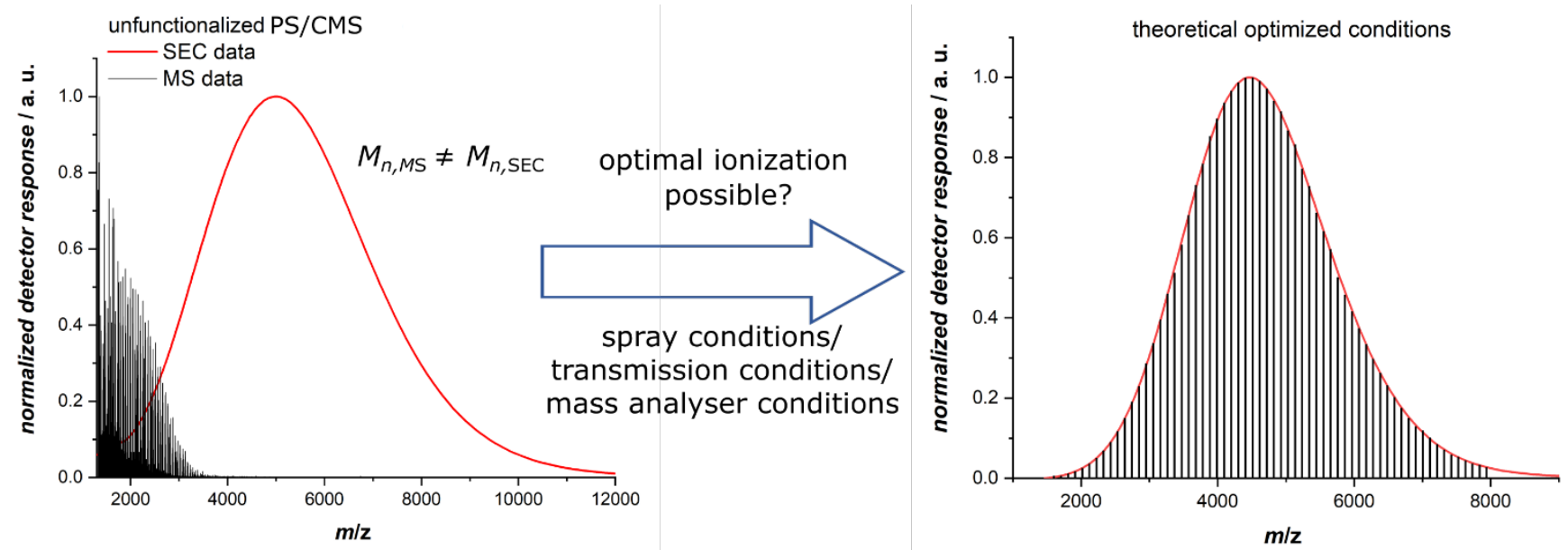

Figure S8. ESI mass spectrum of an unfunctionalized polystyrene/chloromethylstyrene (PS/CMS) copolymer (left, black) ionizing as singlycharged anions via iodide attachment [PS/CMS + I]- compared to the PS-calibrated SEC trace (red). The two data sets show a clear offset in the molar mass distribution, the right panel shows a theoretical optimal ionization resulting in consistent values for both methods.

Figure S8 depicts the ESI mass spectrum of a non-functionalized copolymer consisting of styrene and chloromethyl styrene units (PS/CMS) with a mass distribution known from SEC measurements to be centered around $4500 \mathrm{~g}$ $\mathrm{mol}^{-1}$. The copolymer was ionized as singly-charged iodide adducts [PS/CMS +1$]^{-}$using $100 \mu \mathrm{M}$ sodium iodide and applying standard ionization conditions. ${ }^{2}$ Despite the fact that the mass analyzer used in this study has a range of up to $m / z 8000$ the distribution, consisting of singly-charged ions, falls predominantly in the $m / z<3000$ range. Here, the ESI-mass spectrometry results in an MMD far below the values determined via PS-calibrated SEC.

For the comparison of ionization via chloride attachment and via deprotonation a non-functionalized poly(styrene-co-chloromethylstyrene) and a polystyrene containing a functional carboxyl end-group $\left(\mathrm{PS}_{-} \mathrm{CO}_{2} \mathrm{H}\right)$ were ionized under the same conditions. The polymers with a comparable MMD were ionized in a mixture of $D C M / M e O H$ (3:2) doped with $700 \mu \mathrm{M}$ ammonia. Under the same condition the non-functionalized polymer ionizes via chloride attachment, while the carboxyl functionalized polymer is deprotonated resulting in a much higher ion count as visualized in Figure S9. 


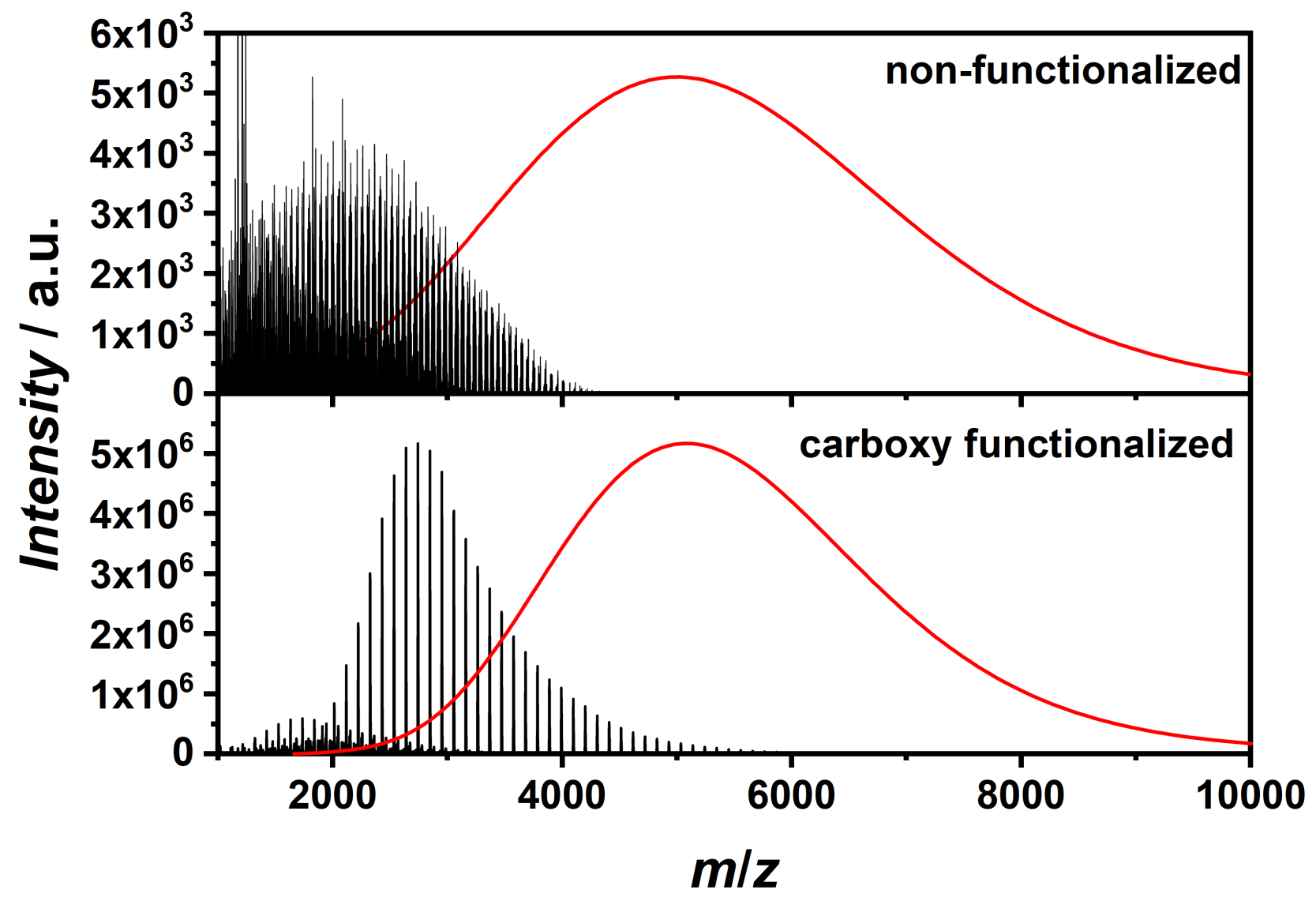

Figure S9. Comparison of non-functionalized singly-charged PS/CMS ionizing via chloride attachment in negative-mode ESI (top) and the carboxyl functionalized pure polystyrene ionizing via deprotonation (bottom). Apart from the additional complexity of the mass spectrum of the PS/CMS copolymer due to the different monomer combinations, similar MMDs are displayed. Nonetheless, the functionalization results in a strong increase of ion current. The respective PS-calibrated SEC traces are given in red for both polymers.

The ionization, transmission and detection conditions were varied within the boundaries of maintaining sufficient signal-to-noise and a stable electrospray. Typically, one parameter was changed at a time to keep the remaining conditions stable. However, due to limitations of the spray stability and the signal intensity in some instances, several dependent parameters were adjusted. For example, when increasing the solvent flow rates, the gas flow rates, or gas temperature might need to be changed for the electrospray to remain stable. Another example would be the reduction of the analyte concentration, with the decrease in signal, other conditions such as the automatic gain control (AGC target) or maximum injection time $\left(\mathrm{IT}_{\max }\right)$ might have to be adjusted to acquire sufficient signal-to-noise at a lower signal intensity. 
Table S3. Overview of systematic variation of the ESI-MS conditions to investigate the change in ionization behavior, the investigated region is given as the lowest and highest investigated value with the optimized value that was used in subsequent measurements after optimization.

\begin{tabular}{|c|c|c|c|}
\hline condition & Lowest value & Highest value & Optimized value \\
\hline S-lens & 20 & 200 & 130 \\
\hline $\begin{array}{l}\text { T (transfer } \\
\text { capillary) }\end{array}$ & $300^{\circ} \mathrm{C}$ & $450^{\circ} \mathrm{C}$ & $320^{\circ} \mathrm{C}$ \\
\hline $\mathbf{I T} \mathrm{T}_{\max }$ & $1 \mathrm{~ms}$ & $500 \mathrm{~ms}$ & $200 \mathrm{~ms}$ \\
\hline AGC target & $2 \times 10^{5}$ & $5 \times 10^{6}$ & $1 \times 10^{6}$ \\
\hline Sheath Gas & 0 & 25 & 8 \\
\hline Spray voltage & $-2.5 \mathrm{kV}$ & $-5 \mathrm{kV}$ & $-3.2 \mathrm{kV}-3.7 \mathrm{kV}$ \\
\hline c (analyte) & $0.0001 \mathrm{mg} \mathrm{mL}^{-1}$ & $4.0 \mathrm{mg} \mathrm{mL}^{-1}$ & $0.1 \mathrm{mg} \mathrm{mL}^{-1}$ \\
\hline $\mathrm{c}\left(\mathrm{NH}_{3}\right)$ & 0.001 v\% & $5 \mathrm{v} \%$ & 0.1 v\% \\
\hline
\end{tabular}

Adjustment of most parameters led to minimal change in the measured MMD while the overall signal intensity was sensitive to suboptimal ionization conditions. Some parameters are interdependent, such as the AGC target and the maximum injection time. The C-trap will inject the ions into the Orbitrap when the AGC target is met, therefore, the $\mathrm{IT}_{\max }$ is only relevant when the AGC target is not met when reaching the maximum injection time. A low $I T_{\max }$ was therefore avoided to achieve representative spectra. Increasing the AGC target over $1 \times 10^{6}$ leads to space charge effects. Therefore, the AGC was maintained at $1 \times 10^{6}$ in later measurements with a high IT $\max$ of $200 \mathrm{~ms}$. In the following Figures S5-S11 the minimum and maximum values for some of the conditions of table S3 were plotted to visualize the relatively similar molecular mass distributions (MMD) even with very different conditions. Some additional information regarding the specific conditions is given in the figure descriptions. 


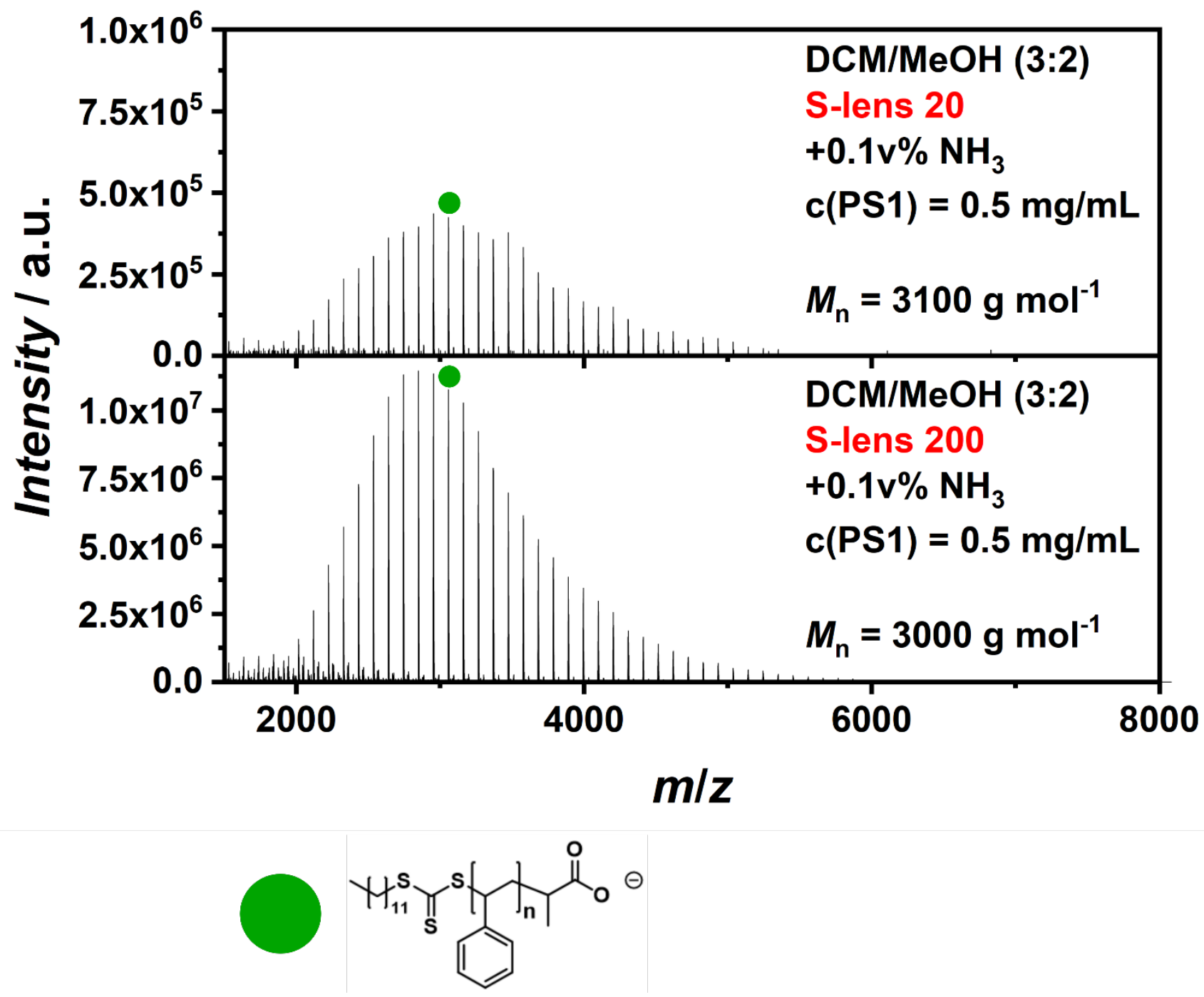

Figure S10. S-lens variation between 20 and 200. Increasing S-lens values leads to an increase of polymer signal, especially in the 0-100 region with minimal changes at values over S-lens 130. 


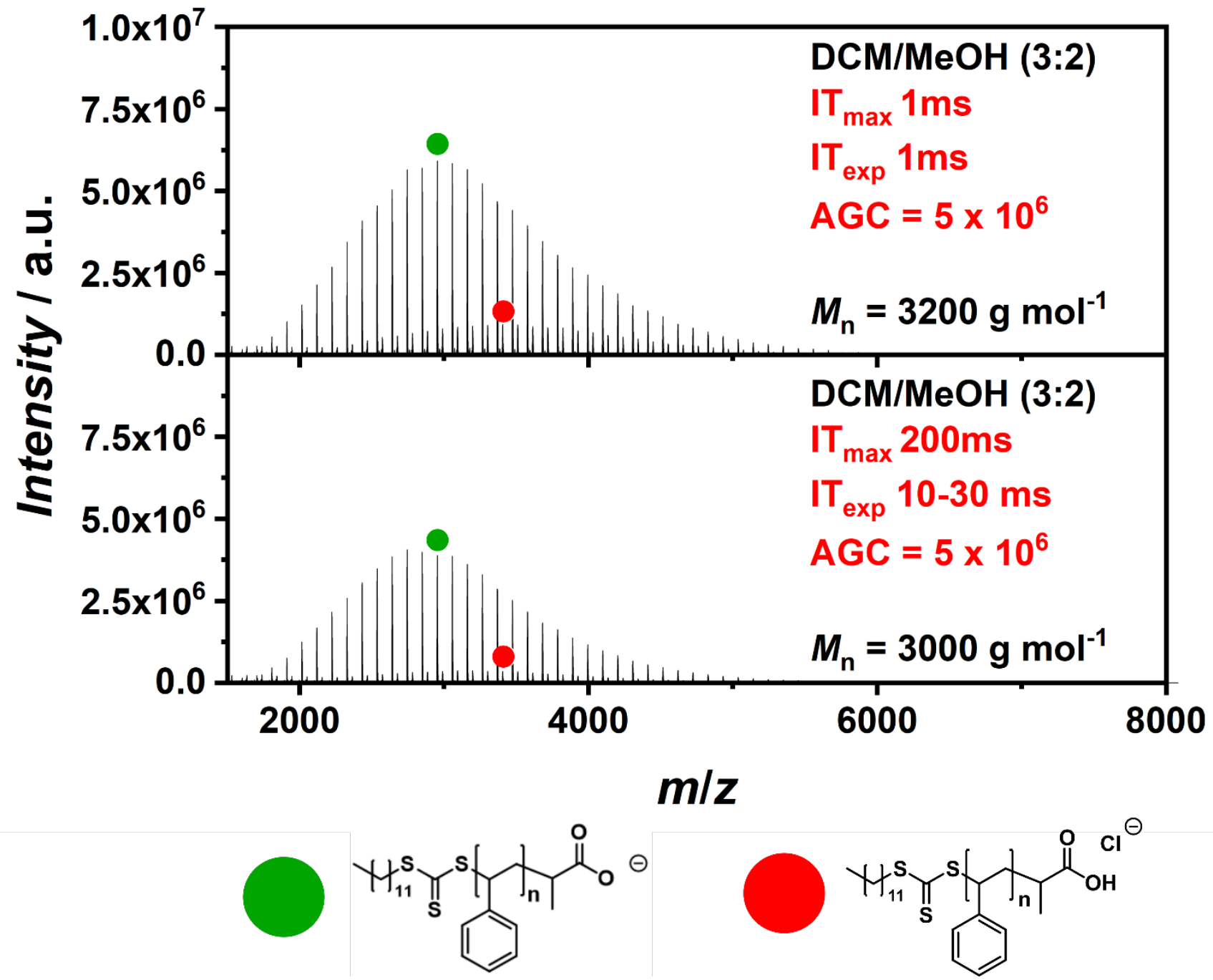

Figure S11. Injection time variation with an increased AGC target and a high maximum injection time resulting in experimental injection times between $10-30 \mathrm{~ms}$. The variation in signal intensity stems from the software normalization of the signal depending on the injection time. Theoretically the spectra should show the same signal intensity. 

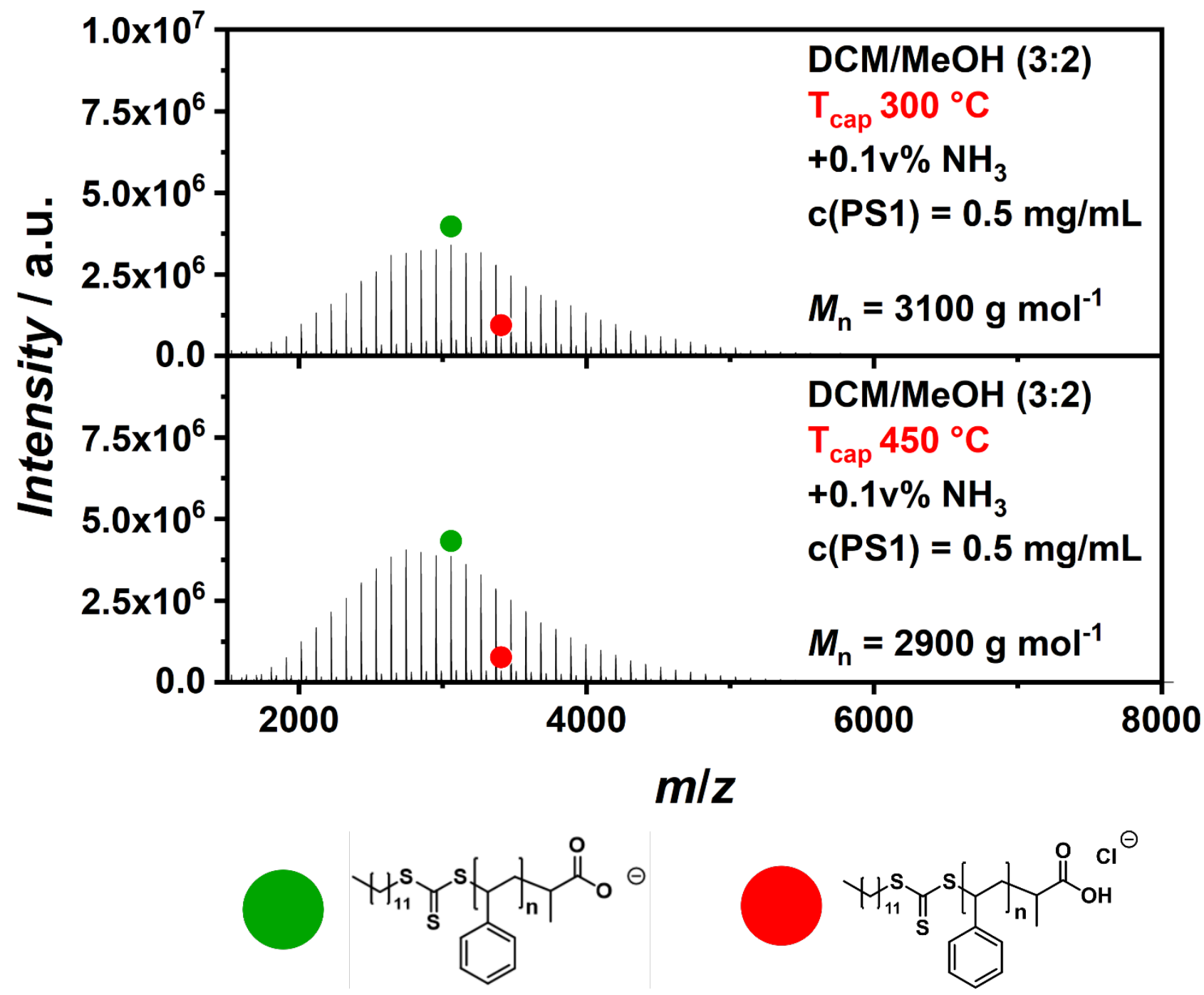

Figure S12. Variation of the transfer capillary temperature during ESI ionization of PS_ $\mathrm{CO}_{2} \mathrm{H}$. 

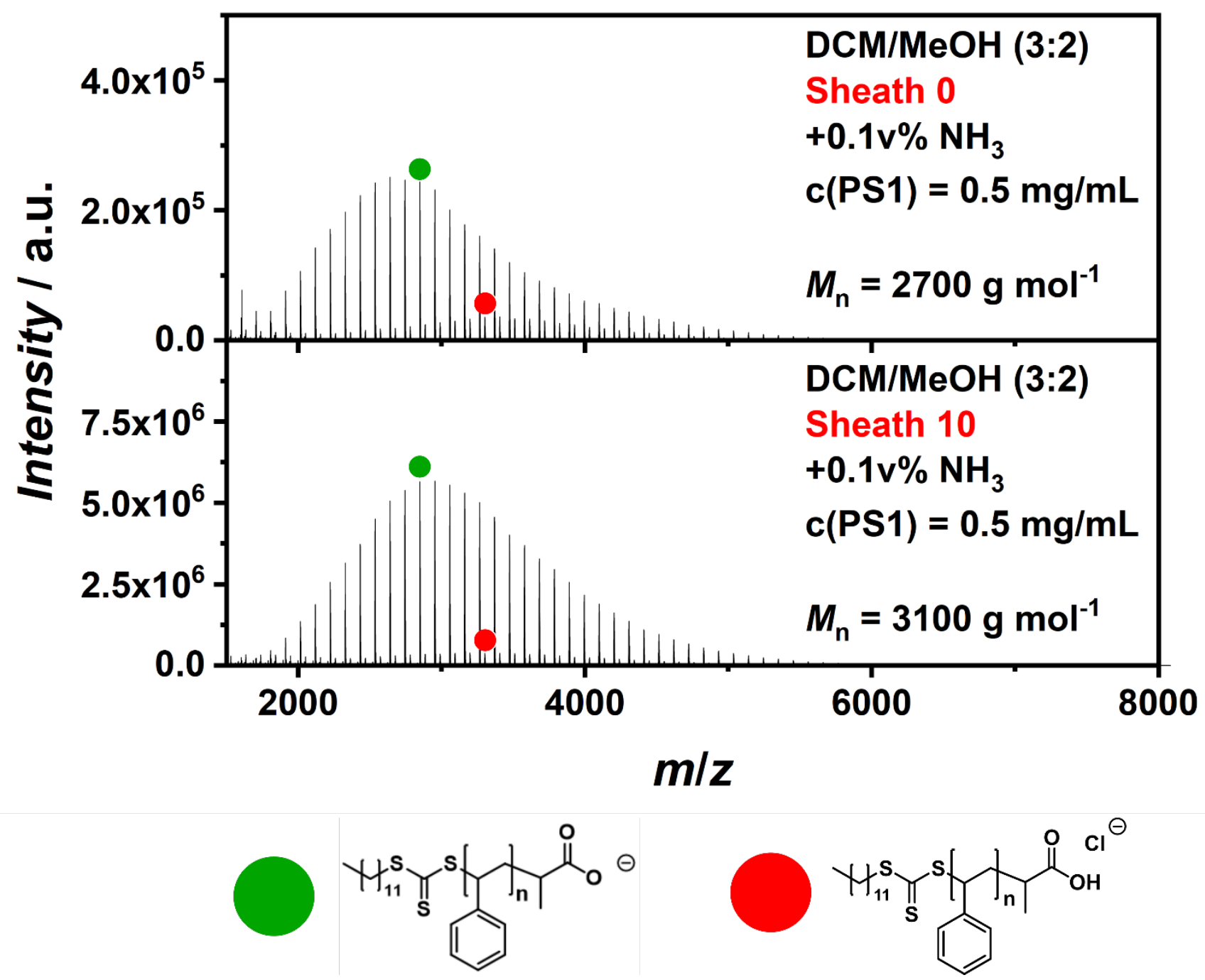

Figure S13. Variation of the sheath gas rate during ESI ionization of $\mathrm{PS}_{-} \mathrm{CO}_{2} \mathrm{H}$.

The gas flow rates were optimized for sample introduction at $5 \mu \mathrm{L} \mathrm{min}{ }^{-1}$, apart from the sheath gas rate, the sweep and auxiliary gas rates can be varied, however, since changes from 0 (arbitrary units) resulted in no change in $\mathrm{MMD}$ and solely in signal reduction, they were maintained at 0 . 


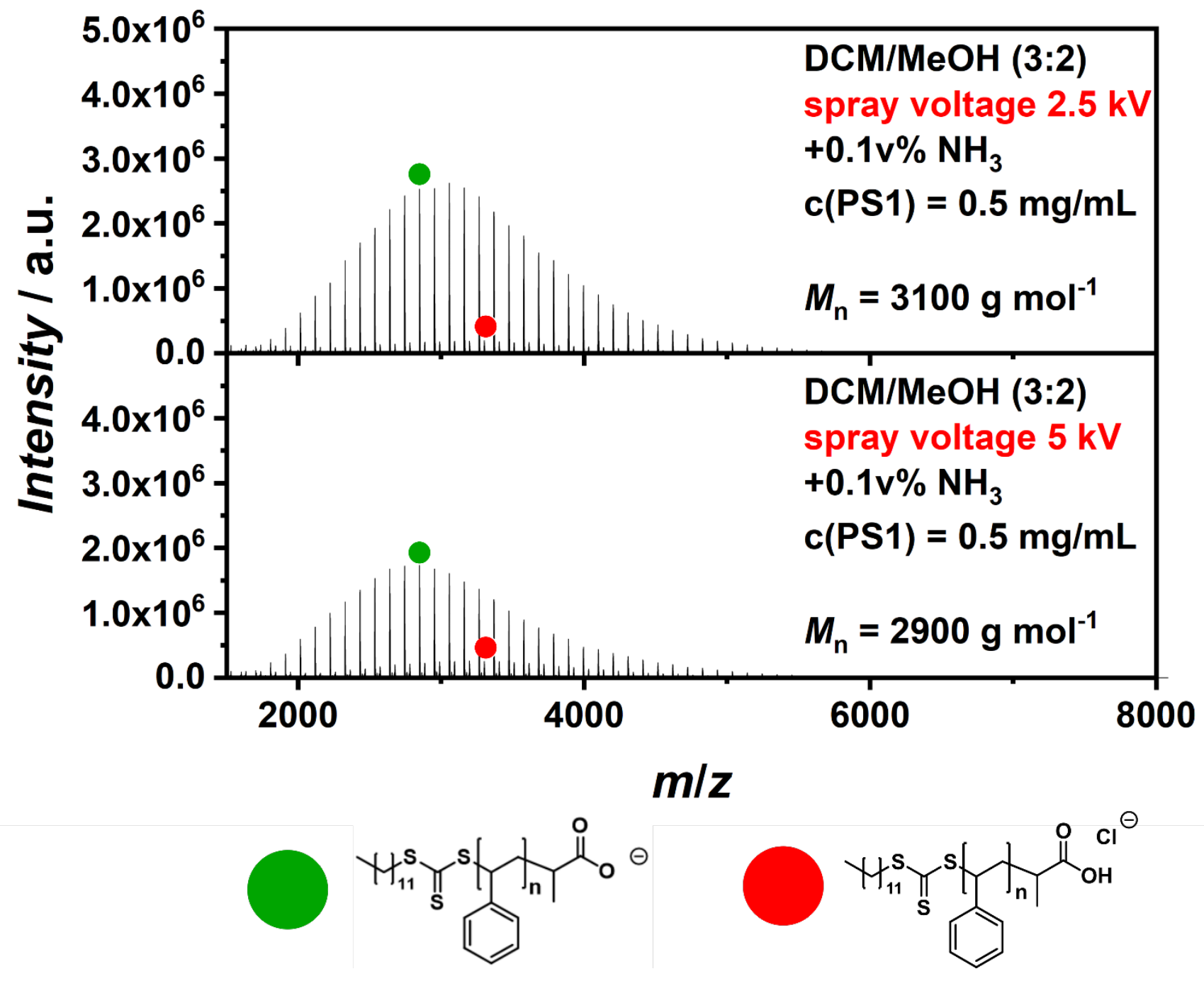

Figure S14. Variation of the spray voltage in the ionization of $\mathrm{PS}_{-} \mathrm{CO}_{2} \mathrm{H}$.

However, the spray voltage is very dependent on the doping of the solvent and the utilized solvent mixture. Therefore, a range was given in the optimized conditions. If an undoped DCM/MeOH solution was used, a spray voltage under $3.5 \mathrm{kV}$ would result in an unstable spray with high TIC variations. 


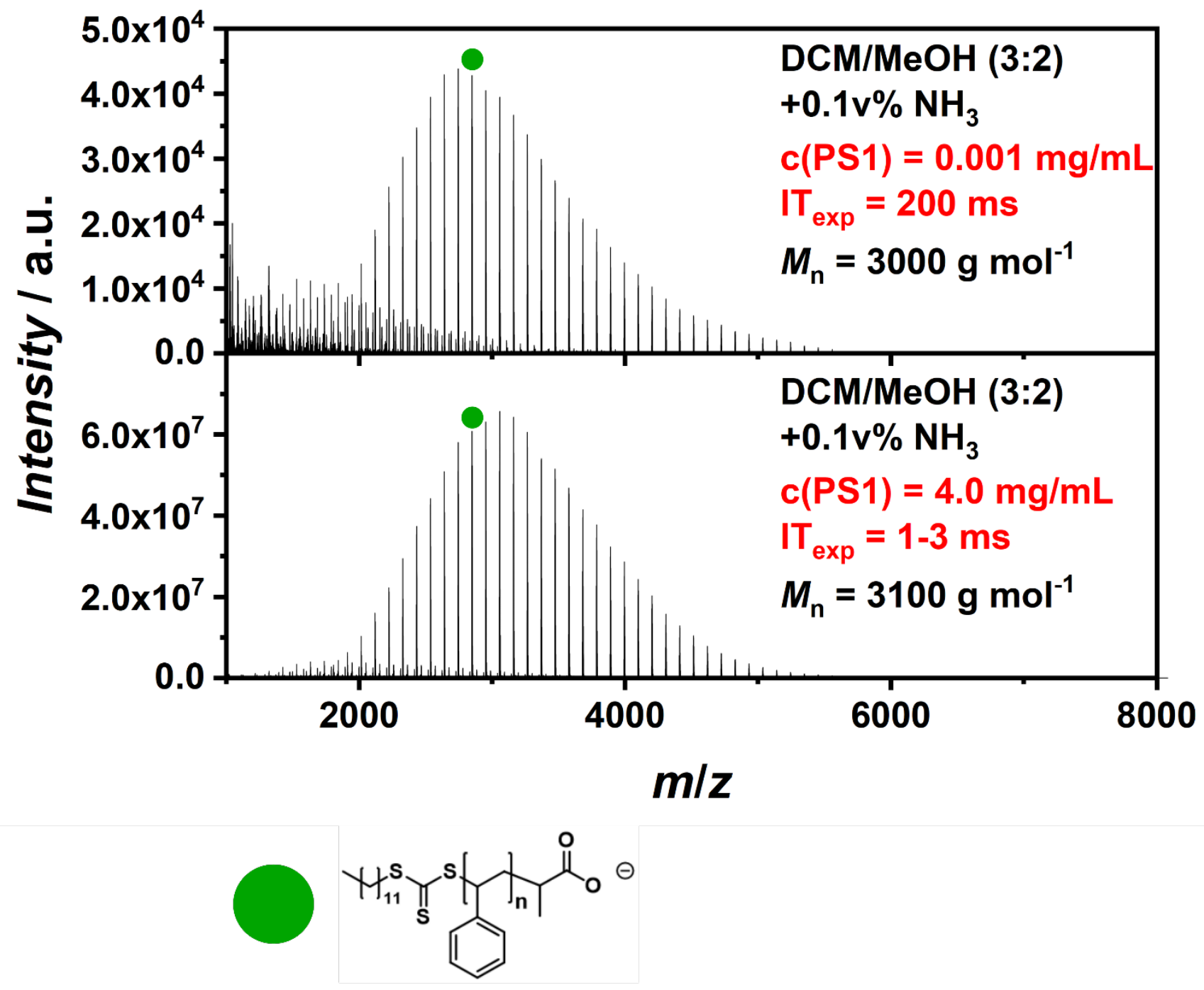

Figure S15. Variation of the analyte concentration for the investigation of the $\mathrm{PS}_{-} \mathrm{CO}_{2} \mathrm{H}$ ionization.

The variation of the sample concentration was carried out during the optimization of the ESI-MS (Figure S15). Since these experiments were carried out with a declustering potential of $150 \mathrm{~V}$, no cluster ions were observed. The utilized concentration in most experiments shown in the main text was $10-20 \mu \mathrm{M}$ for the entire polymer distribution. Depending on the sample $\left(0.1 \mathrm{mg} \mathrm{mL}^{-1}=21 \mu \mathrm{M}\right.$ for PS_CO$\left.{ }_{2} \mathrm{H}\right)$ this represents ca. $1 \mu \mathrm{M}$ for the most abundant, individual polymer chain size $(M p)$. As observed in Figure S15, the signal deteriorated with the decrease in concentration and no strong influence on the MMD was observed at the lowest investigated analyte concentration of $0.001 \mathrm{mg} \mathrm{mL}^{-1}$, which corresponds to $210 \mathrm{nM}$ for the entire distribution and $10 \mathrm{nM}$ for $\mathrm{Mp}$. Interestingly, the polymer concentration can be decreased up to $0.001 \mathrm{mg} \mathrm{mL}^{-1}$ (Figure S15) and an ESI-MS spectrum can still be obtained although higher IT $\max$ values are required. Overall, apart from extreme low concentrations the MMD does not shift between $0.1-4 \mathrm{mg} \mathrm{mL}^{-1}$ 


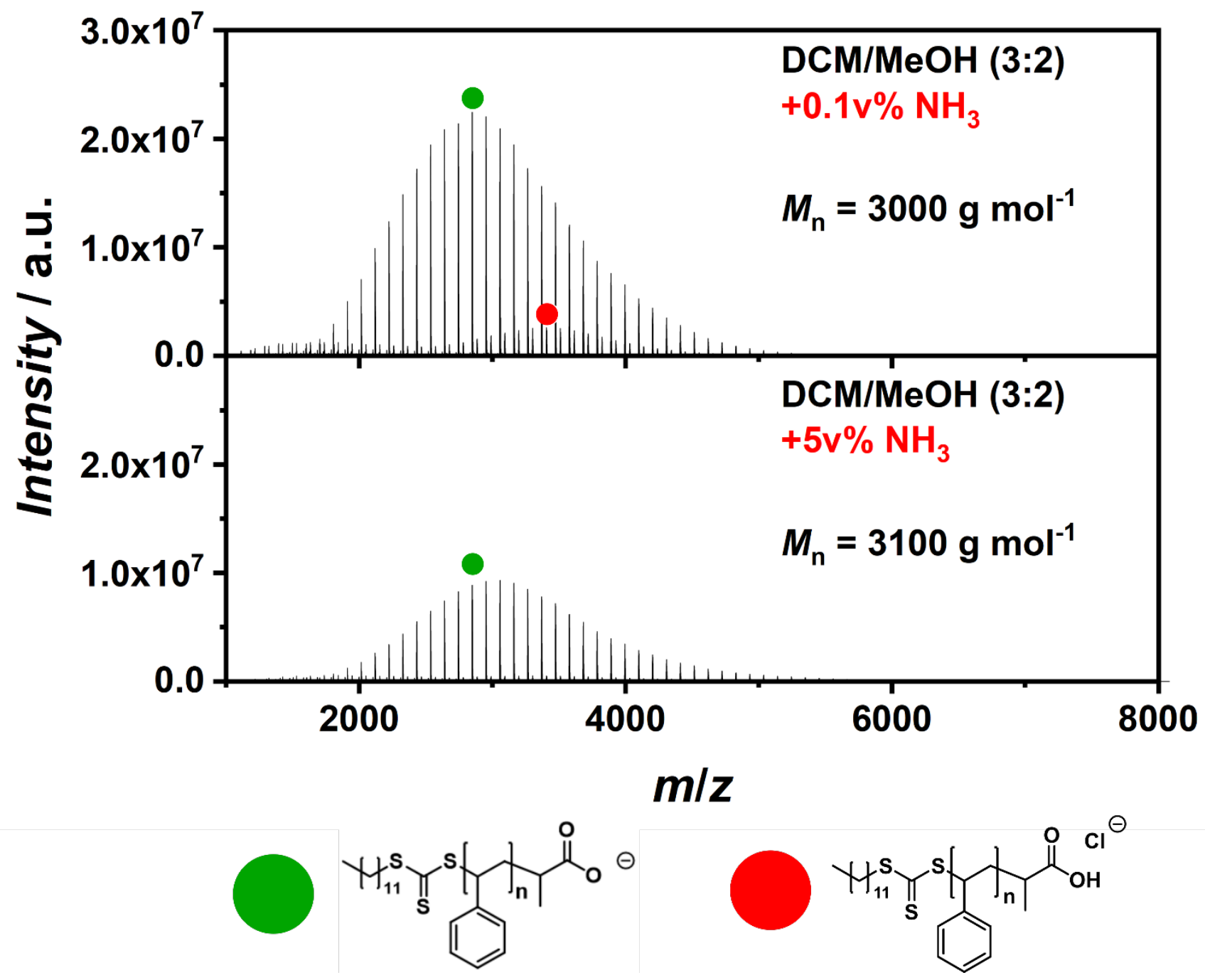

Figure S16. Variation of the $\mathrm{NH}_{3}$ doping concentration in the ESI-MS ionization study on $\mathrm{PS} \mathrm{CO}_{2} \mathrm{H}$. 


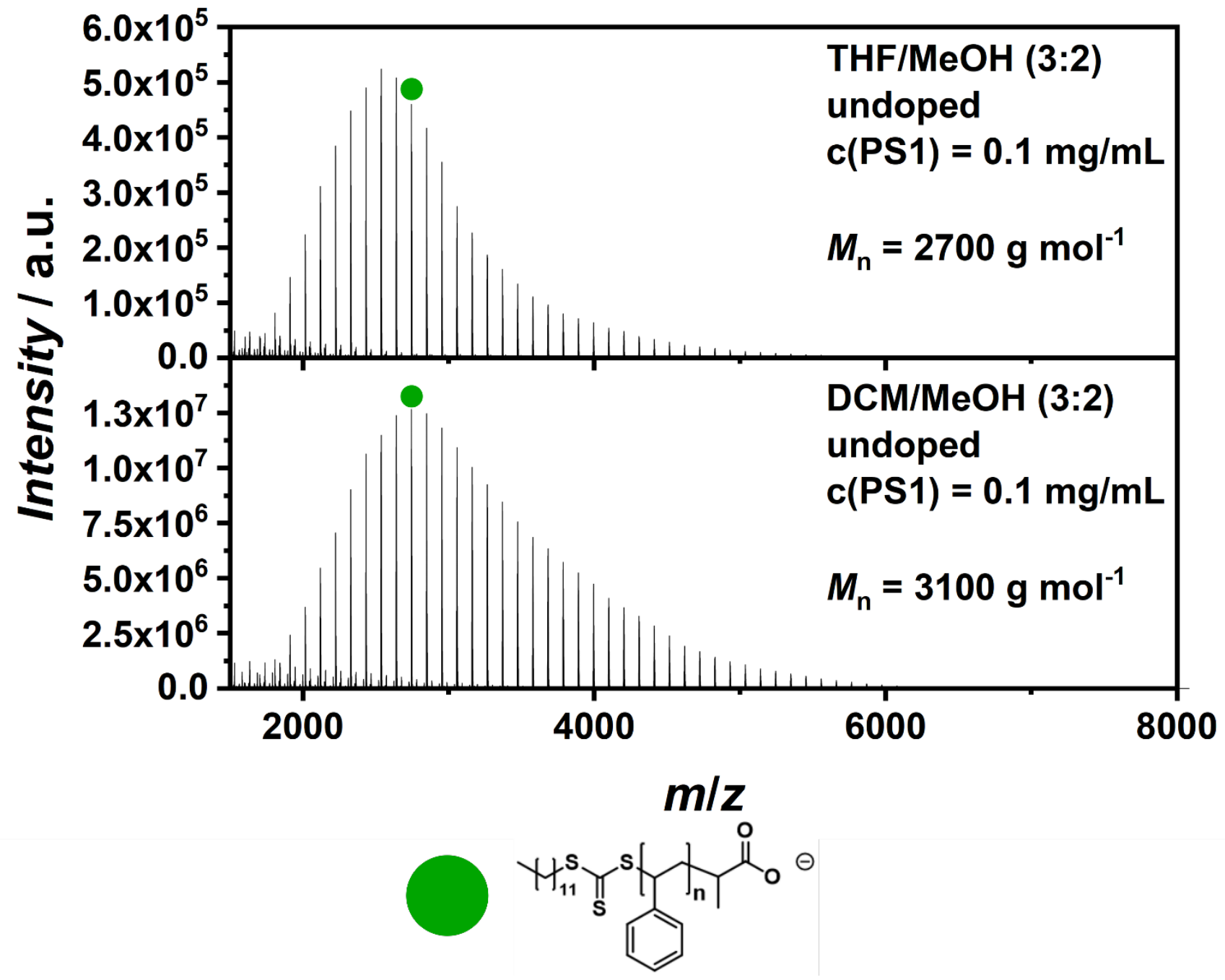

Figure S17. PS_CO ${ }_{2} \mathrm{H}$ measured in THF/MeOH (3:2) and DCM/MeOH (3:2) ionizing as $\left[\mathrm{PS}_{-} \mathrm{CO}_{2} \mathrm{H}-\mathrm{H}^{-}\right.$without ammonia doping resulting in a higher MMD for DCM as the nonpolar component in the solvent mixture.

Interestingly, the same doped solution does not show a difference in MMD and shows an MMD similar to the undoped DCM/MeOH mixture (Figure S17). 

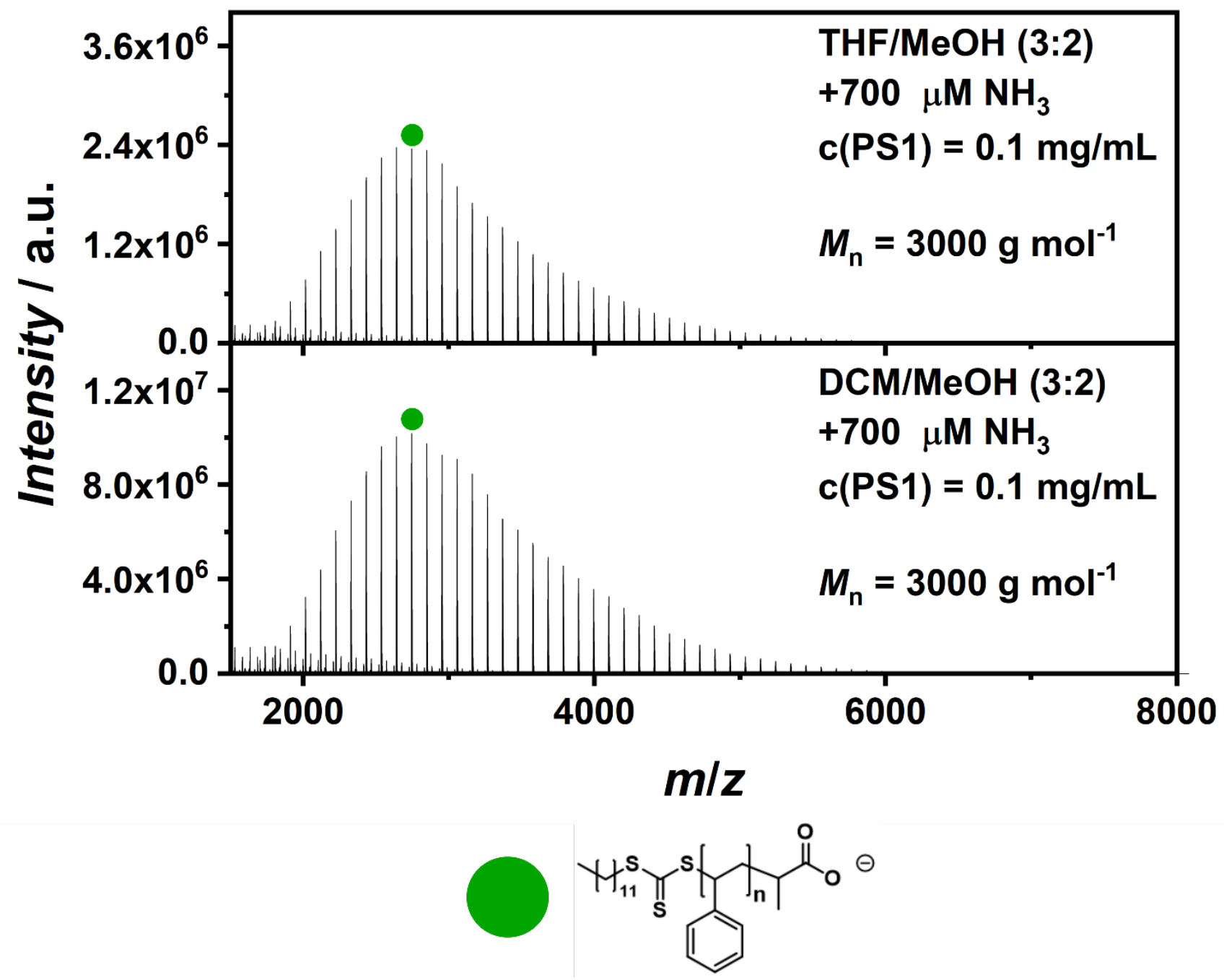

Figure S18. Ionization behavior of $\mathrm{PS}_{-} \mathrm{CO}_{2} \mathrm{H}$ ionizing as $\left[\mathrm{PS}_{-} \mathrm{CO}_{2} \mathrm{H}-\mathrm{H}\right]^{-}$in doped mixtures of DCM/MeOH and THF/MeOH showing no difference in MMD. 

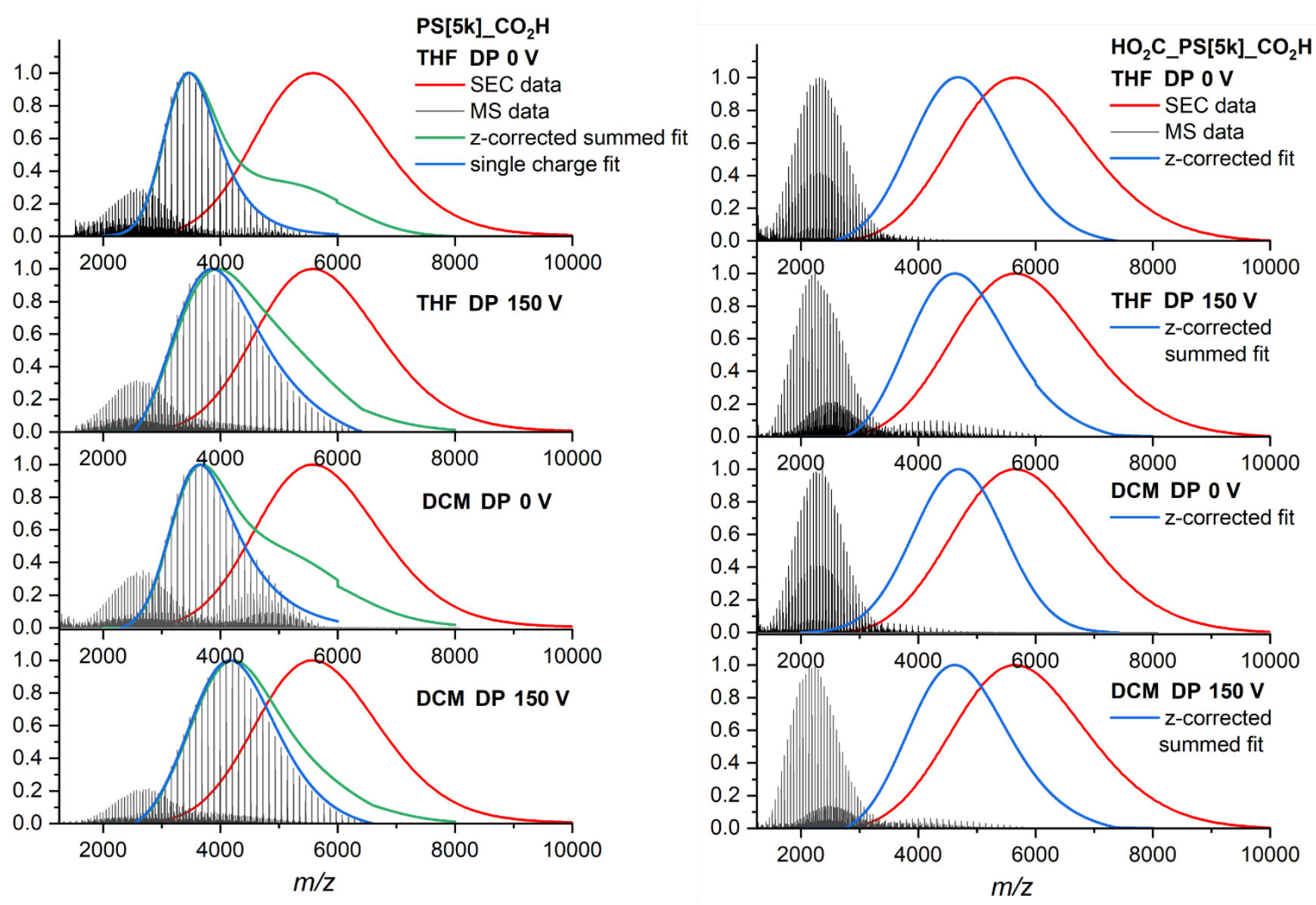

\begin{tabular}{ccccc} 
Sample & solvent & $\begin{array}{c}\text { DP } \\
\text { [V] }\end{array}$ & TIC & Overlap [\%] \\
\hline PS[5k]_CO ${ }_{2} \mathrm{H}$ & THF & 0 & $2.9 \times 10^{7}$ & 34 \\
PS[5k]_CO ${ }_{2} \mathrm{H}$ & THF & 150 & $1.2 \times 10^{8}$ & 47 \\
PS[5k]_CO ${ }_{2} \mathrm{H}$ & DCM & 0 & $1.0 \times 10^{8}$ & 45 \\
PS[5k]_CO ${ }_{2} \mathrm{H}$ & DCM & 150 & $3.5 \times 10^{8}$ & 44 \\
$\mathrm{HO}_{2}$ C_PS[5k]_CO ${ }_{2} \mathrm{H}$ & THF & 0 & $8.0 \times 10^{7}$ & 51 \\
$\mathrm{HO}_{2}$ C_PS[5k]_CO ${ }_{2} \mathrm{H}$ & THF & 150 & $2.7 \times 10^{8}$ & 52 \\
$\mathrm{HO}_{2}$ C_PS[5k]_CO ${ }_{2} \mathrm{H}$ & DCM & 0 & $1.8 \times 10^{8}$ & 47 \\
$\mathrm{HO}_{2}$ C_PS[5k]_CO ${ }_{2} \mathrm{H}$ & DCM & 150 & $6.2 \times 10^{8}$ & 51 \\
\hline
\end{tabular}

Figure S19. Solvent and declustering potential variation of mono-(left) and difunctionalized- (right) carboxyl-PS samples with MMDs in the detector range for $z=1$. Distributions are compared by the overlap between SEC (red) and ESI-MS (black) distribution. The blue fit functions show the overlap between SEC and MS with all species excluding the recombination termination product $\left[\mathrm{PS}_{\mathrm{RC}}-2 \mathrm{H}\right]^{2-}$, the recombination product was included in the green curve and in the table values in this figure. 


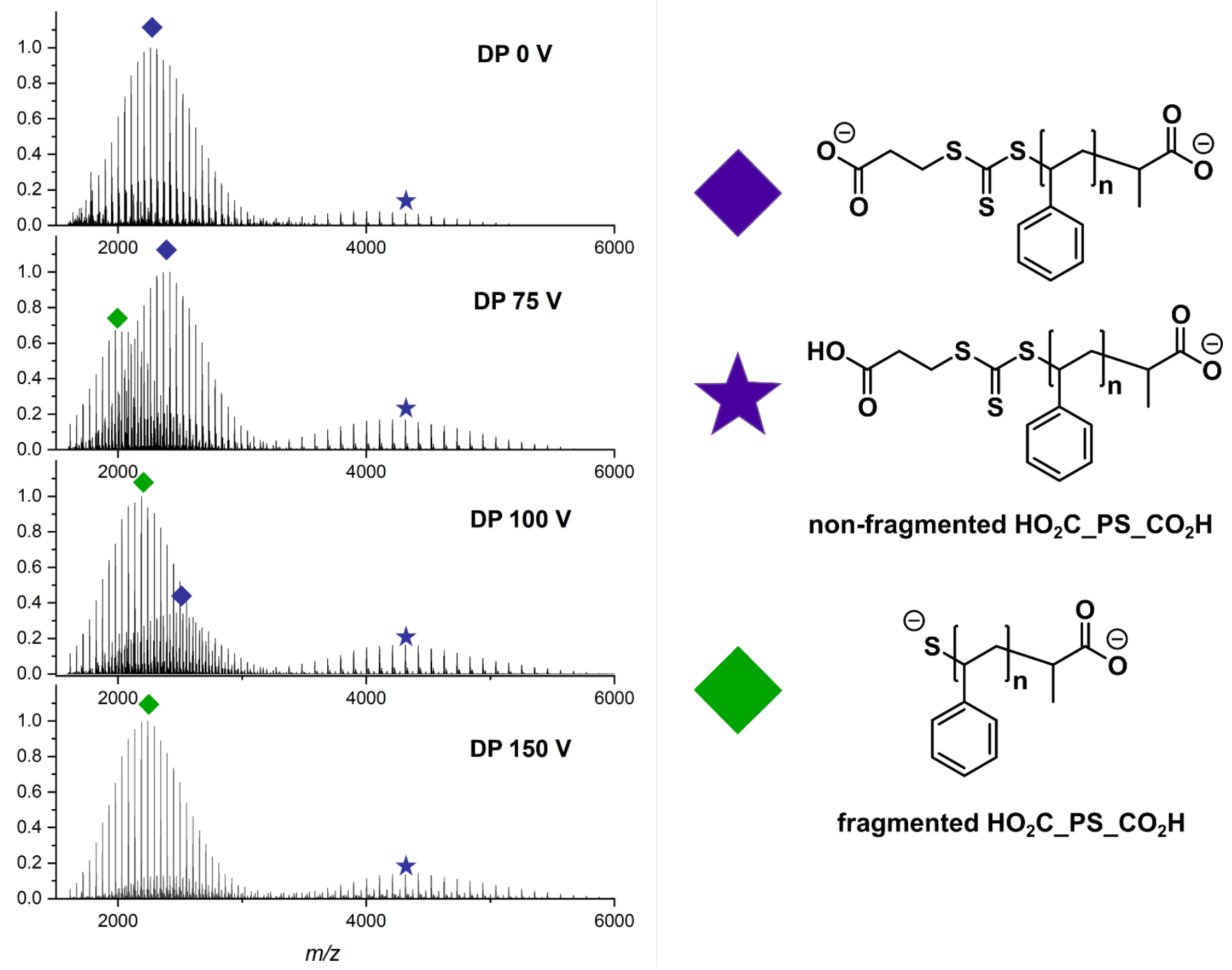

Figure S20. ESI mass spectra of a dicarboxyl functionalized polystyrene $\left(\mathrm{HO}_{2} \mathrm{C}\right.$-PSF3_CO$\left.{ }_{2} \mathrm{H}\right)$ measured with varying declustering potentials (DP) displaying increasing fragmentation of the doubly-charged signals with higher declustering potentials. 


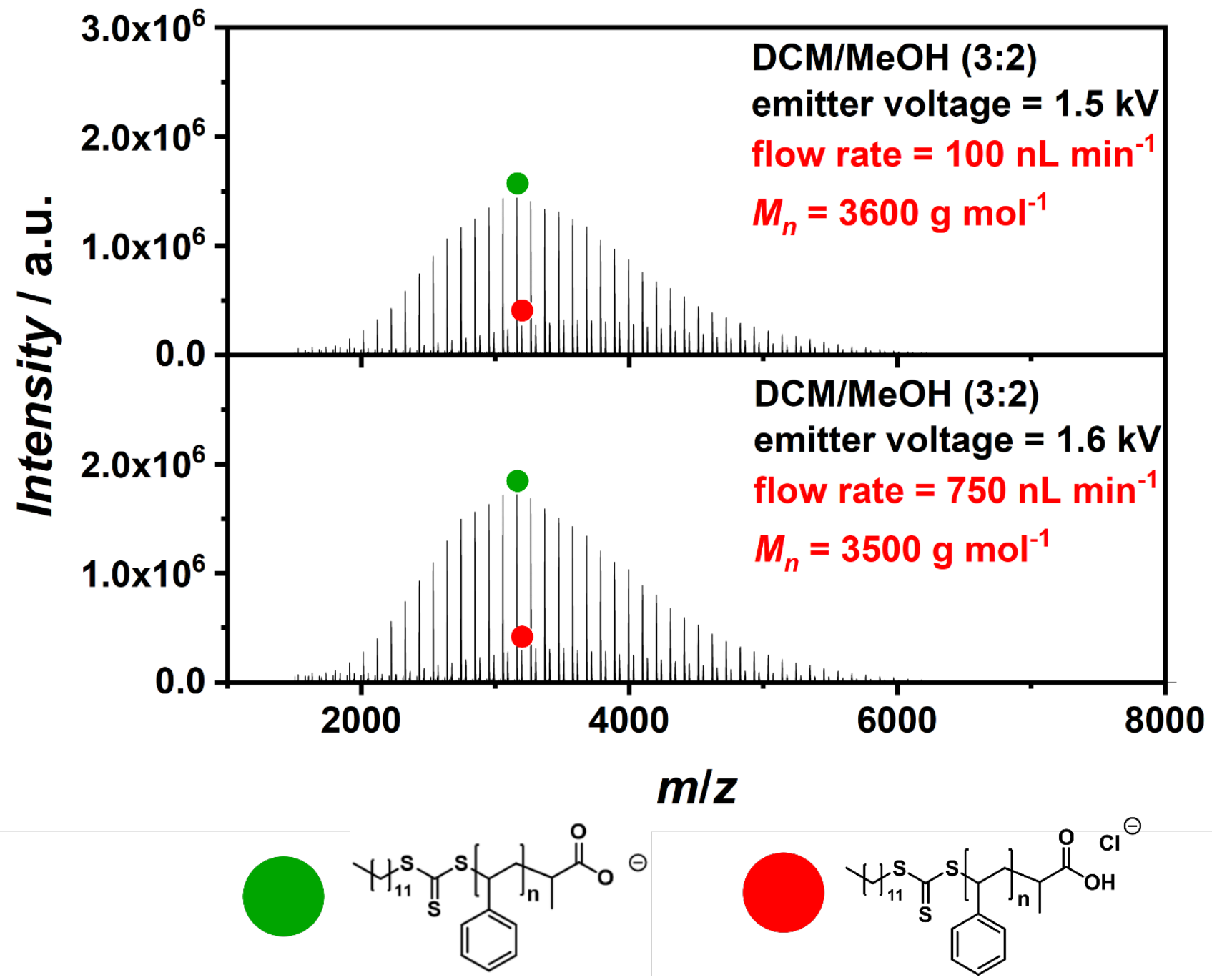

Figure S21. ESI-MS ionization of PS_ $\mathrm{CO}_{2} \mathrm{H}$ under nanoESI conditions at a concentration of $0.1 \mathrm{mg} \mathrm{mL}^{-1}$ in a solvent mixture of DCM/MeOH (3:2), doped with $0.1 \mathrm{v} \%$ ammonia. A range of solvent flow rates were tested with 100 and $750 \mathrm{~nL} \mathrm{~min}^{-1}$ as the highest variation, the emitter voltage was slightly changed to achieve a stable spray. 


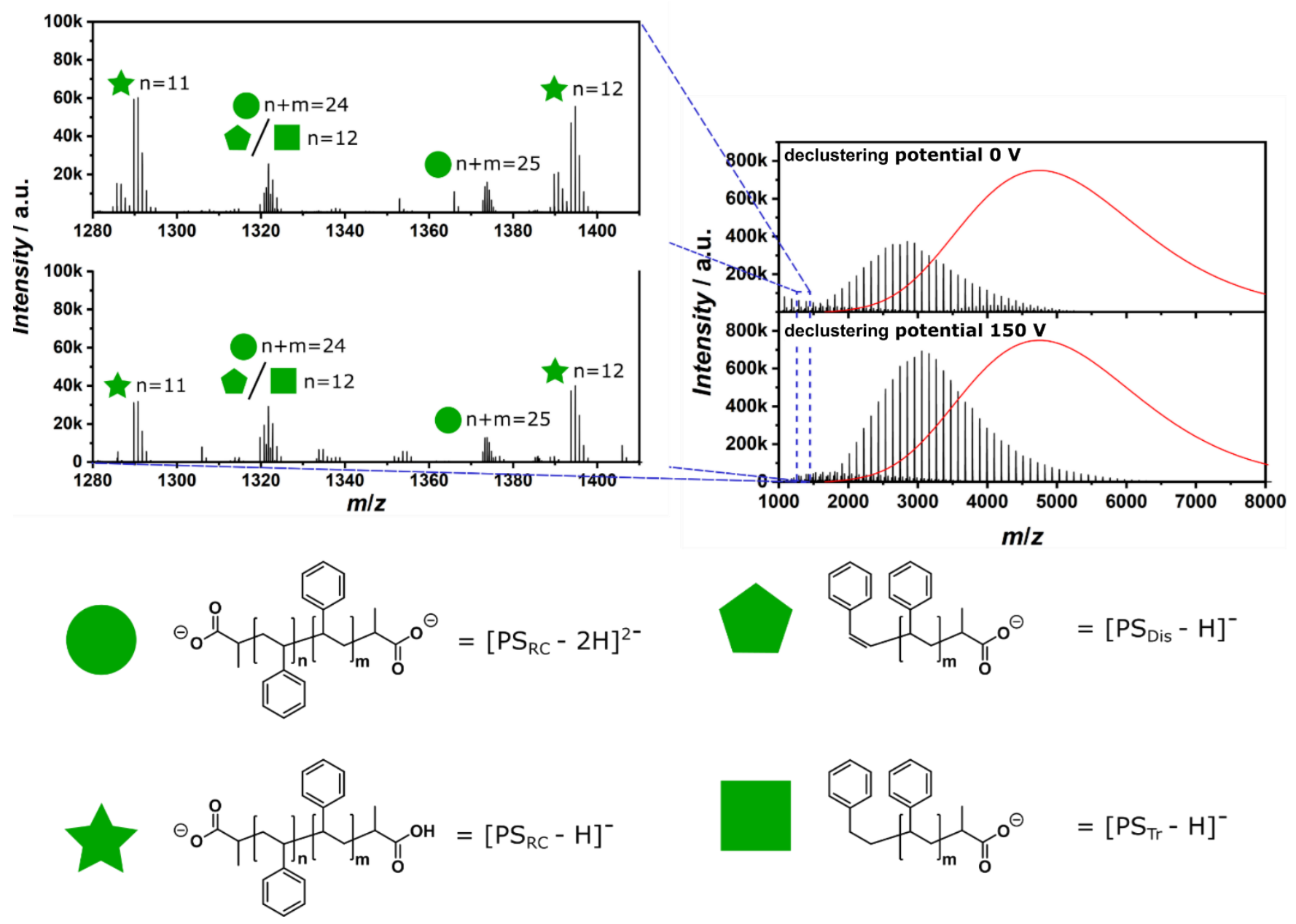

Figure S22. Characterization of the low $\mathrm{m} / \mathrm{z}$ region in the ESI mass spectra of the $\left[\mathrm{PS}_{-} \mathrm{CO}_{2} \mathrm{H}-\mathrm{H}\right]^{-}$shown in Figure 2, showing side products stemming from the termination of the RAFT polymerization of PS_ $\mathrm{CO}_{2} \mathrm{H}$.

\section{References}

(1) Ritter, A.; Schmid, M.; Affolter, S. Determination of Molecular Weights by Size Exclusion Chromatography (SEC) - Results of Round Robin Tests. Polym. Test. 2010, 29 (8), 945-952. https://doi.org/10.1016/j.polymertesting.2010.08.002.

(2) Nitsche, T.; Blanksby, S. J.; Blinco, J. P.; Barner-Kowollik, C. Pushing the Limits of Single Chain Compaction Analysis by Observing Specific Size Reductions via High Resolution Mass Spectrometry. Polym. Chem. 2020, 11 (10), 1696-1701. https://doi.org/10.1039/C9PY01910C. 